\title{
Can adherence to antihypertensive therapy be used to promote adherence to statin therapy?
}

\author{
This article was published in the following Dove Press journal: \\ Patient Preference and Adherence \\ 12 August 2009 \\ Number of times this article has been viewed
}

\author{
Richard H Chapman' \\ Elise M Pelletier' \\ Paula J Smith' \\ Craig S Roberts ${ }^{2}$ \\ 'US Health Economics and Outcomes \\ Research, IMS Health, Falls Church, \\ VA, USA; ${ }^{2}$ Global Outcomes Research, \\ Pfizer Inc, New York, NY, USA
}

Objective: To compare adherence with statin therapy in patients switching to single-pill amlodipine besylate/atorvastatin calcium with patients adding a separate statin to their amlodipine regimen.

Methods: We identified hypertensive patients prescribed amlodipine who switched to amlodipine/atorvastatin (switch) or added a statin to their amlodipine regimen (add-on) from July 2004 to June 2007. Propensity score matching (1 switch:3 add-on) was applied based on 'nearest neighbor' approach. The primary adherence measure was patients with proportion of days covered (PDC) $\geq 0.80$ at 180 days; secondary measures included mean PDC and persistence. A sensitivity analysis was performed, accounting for total statin/amlodipine exposure.

Results: Among 4556 matched patients ( $n=1139$ switch; $n=3417$ add-on), mean age was 53.9 years and $52.1 \%$ were male. After 180 days, adherence with statin therapy was higher for the switch vs add-on cohort $(50.8 \%$ vs $44.3 \% ; P<0.001)$. After adjusting for pre-index amlodipine adherence, the switch cohort was more likely to be adherent than the add-on cohort (odds ratio: 1.64 [95\% confidence interval: 1.42 to 1.89]). Persistence was higher in the switch than the add-on cohort (127.6 vs 117 days; $P<0.001$ ).

Conclusion: Hypertensive patients taking amlodipine who initiated statin therapy via single-pill amlodipine/atorvastatin were more likely to remain adherent to their statin than patients adding a separate statin to their antihypertensive regimen.

Keywords: adherence, amlodipine, atorvastatin, cardiovascular disease, persistence, single-pill

\section{Introduction}

Cardiovascular disease (CVD) remains the leading cause of death in developed countries, and accounts for more than one-third of deaths in the United States. ${ }^{1}$ The co-occurrence of risk factors for CVD - including hypertension, dyslipidemia, diabetes, current smoking, and being overweight - is associated with a markedly increased risk of cardiovascular events. ${ }^{2,3}$ Of the numerous factors that contribute to cardiovascular risk, hypertension and dyslipidemia are highly prevalent either alone or in combination. ${ }^{4-6}$ Indeed, hypertension rarely occurs in isolation from other risk factors for CVD. ${ }^{6,7}$

The beneficial reduction in the risk of cardiovascular events provided by antihypertensive and lipid-lowering therapy has been confirmed through numerous clinical trials and meta-analyses. ${ }^{8-12}$ However, attainment of guideline-recommended blood pressure (BP) and low-density lipoprotein cholesterol (LDL-C) goals in real-world clinical practice is low, ${ }^{6,713}$ despite the availability of effective treatments. The 2008 EUROASPIRE III survey in primary care across 12 European countries recently
Principal, US Health Economics and Outcomes Research, IMS Health, 300 N.Washington Street, Suite 303 Falls Church,VA 22046, USA

Tel + I 7032862869

Fax +l 7032862899

Email rchapman@us.imshealth.com 
concluded that individuals at high risk of CVD are not being managed effectively (in-line with 2003 European guidelines ${ }^{14}$ ) as only $26 \%$ had controlled BP $(<140 / 90 \mathrm{mmHg})$ and only $31 \%$ had LDL-C $<2.5 \mathrm{mmol} / \mathrm{L}(96 \mathrm{mg} / \mathrm{dL}) .{ }^{15}$ These data are in line with a 2006 analysis of the US National Health and Nutrition Examination Survey (NHANES) database which reported that $47 \%$ of the surveyed population had hypercholesterolemia, and only $11 \%$ of these had their lipids controlled (LDL-C $<120 \mathrm{mg} / \mathrm{dL}$ ). ${ }^{6}$ Furthermore, 30\% had hypertension, but only $41 \%$ of hypertensive patients had their BP controlled $(<140 / 90 \mathrm{mmHg}){ }^{6}$

Inadequate adherence to antihypertensive and lipidlowering medications likely contributes to this failure to attain $\mathrm{BP}$ and/or LDL-C goals, as poor adherence is associated with suboptimal clinical outcomes. ${ }^{16-20}$ For example, in a study of a large managed care cohort, both therapy intensification and medication adherence were important components for achieving recommended BP goals. ${ }^{18}$

When examining the outcomes from a retrospective study of patients with comorbid hypertension and dyslipidemia who initiated therapy with separate prescriptions for antihypertensive and lipid-lowering medications, we found that while $58 \%$ of patients were adherent with their antihypertensive therapy at 6 months, only $43 \%$ were adherent with their lipid-lowering medication. ${ }^{21}$ Thus, there may be potential for improving adherence with concurrent antihypertensive and lipid-lowering therapies simply by increasing adherence with lipid-lowering therapy to levels observed with antihypertensives.

Potential strategies for improving adherence with therapy include simplification of a drug regimen with the use of single-pill combination therapies, which reduces a patient's pill burden and also synchronizes the initiation of concomitant therapies. $^{22-25}$ Single-pill amlodipine/atorvastatin is the first fixed-dose combination that includes an antihypertensive and a statin to treat multiple risk factors for CVD. ${ }^{26-28}$ The single-pill formulation has been shown to improve adherence compared with a two-pill regimen in patients without prior experience of calcium channel blocker or statin therapy. ${ }^{29}$ However, it is not currently known whether the use of single-pill therapy can help to increase patients' adherence with statin therapy to the levels of adherence observed with antihypertensives. We therefore sought to determine whether adherence with new statin therapy in patients already receiving amlodipine is better among patients who switch to single-pill amlodipine/atorvastatin compared with patients in whom a separate statin is added on to their existing amlodipine therapy.

\section{Methods}

\section{Study design}

We conducted a retrospective cohort study using the PharMetrics Patient-Centric Database (Watertown, MA, USA), which is a large, nationally representative database including US enrollees across approximately 90 US health insurance plans. The database is composed of fully adjudicated medical and pharmaceutical claims from more than 55 million unique patients, and contains over 2 billion healthcare transactions, including prescriptions, office visits, hospital stays, and diagnostic tests. Patients in the database are representative of the national commercially insured population on a variety of demographic measures. ${ }^{30}$ Treatment in long-term care settings, such as nursing homes and hospices, is not included.

We identified adults (aged $\geq 18$ years) who filled a new prescription for either single-pill amlodipine/atorvastatin or a statin during a 36-month period (July 1, 2004 to June 30, 2007); the prescription fill date of the initial amlodipine/atorvastatin or statin prescription was considered the index date. Patients were excluded who had: a single-pill amlodipine/atorvastatin or statin prescription during the 360 days prior to the index date; no evidence of amlodipine use from 360 days pre-index date through 30 days post-index date; an amlodipine prescription on the same day as the single-pill amlodipine/atorvastatin prescription; or no evidence of a diagnosis of hypertension pre-index through the index date. Patients were also excluded if they were aged $\geq 65$ years and not enrolled in a Medicare Risk plan (complete claims histories may not be available for patients aged $\geq 65$ years without Medicare Risk coverage due to benefit coordination issues with other payers). All patients were continuously enrolled for 360 days before and 180 days after the index date and had either a pre-index amlodipine prescription with at least one day's supply that spanned over the index date or an amlodipine prescription in both the pre- and post-index periods. Patients were followed for 180 days post-index date to maximize data availability and increase the number of patients eligible for inclusion.

\section{Study population}

Patients meeting the study criteria were divided into two cohorts: (1) amlodipine/atorvastatin switch cohort: patients on amlodipine who switched to single-pill amlodipine/ atorvastatin, and (2) statin add-on cohort: patients on amlodipine who added statin therapy.

Because we hypothesized that disease severity and other unobserved patient characteristics could be associated with medication choice, patients were matched in a 1:3 ratio 
(single-pill switch: statin add-on) based on propensity score weighting. Logistic regression was used to calculate the propensity score as the likelihood of being in the single-pill atorvastatin/amlodipine cohort vs the statin add-on cohort based on pre-index variables. Variables included in the propensity score model were: age, gender, plan type, payer type, geographic region, total number of pre-index antihypertensive prescription classes, and comorbidity index score (Dartmouth-Manitoba adaptation of the Charlson comorbidity index). ${ }^{31}$ Each patient was calculated a unique probability score of being in a given medication cohort, which was used to match patients from each cohort. Patients were matched based on a 'nearest neighbor' approach, defined by a minimal difference $(e g, \pm 0.001)$ in the fitted probability of amlodipine/atorvastatin use..$^{32,33}$

\section{Adherence}

Measures of adherence, including the proportion of patients achieving adherence and persistence, were compared between the amlodipine/atorvastatin switch and statin add-on cohorts.

Adherence was calculated as the proportion of days covered (PDC) during the 180-day follow-up period. $\mathrm{PDC}$ is the proportion of days in the study period that the treatment regimen is available to the patient, as observed from pharmacy claims data and medical records. In scenarios where an overlap in medication refills existed, unique days with drug on hand were counted. Days supply falling beyond the 180-day study period was truncated and not used in the PDC calculation. For the proportion of patients achieving adherence, patients were considered 'adherent' if PDC $\geq 0.80 . .^{16,19,21,29,34-36}$ Patients were considered 'persistent' for the number of consecutive days from therapy initiation to the first 30-day gap in therapy.

Since patients could switch to and from different statins or combinations of statins and amlodipine, a sensitivity analysis was conducted on the total amlodipine and statin exposure in the post-index period. Under this analysis, any use of either amlodipine or a statin in either cohort was considered 'adherent' (eg, patients from the statin add-on cohort who switched to single-pill amlodipine/atorvastatin were still credited as receiving amlodipine and statin prescriptions and vice versa). Adherence measures for amlodipine and statin were considered separately and compared for each cohort.

\section{Statistical analyses}

The primary analysis compared the likelihood of achieving adherence ( $\mathrm{PDC} \geq 0.80$ ) to statin therapy using generalized linear models for each of the matched cohorts, controlling for prior amlodipine adherence and history of CVD.
Comparisons of adherence rates and proportions achieving adherence used Wilcoxon rank-sum tests for continuous variables and chi-square tests for categorical variables. Kaplan-Meier analysis was carried out to estimate the proportion of patients who remained persistent with the index drug by cohort. The probability of remaining persistent with therapy in each interval was calculated based on the number of patients still being followed who had not been excluded through each interval. Patients were censored at either the point of discontinuation of the index medication or the point of eligibility loss from the Health Plan database, whichever occurred first. Data extractions and statistical analyses were performed using $\mathrm{SAS}^{\circledR}$ software versions 8.2 and 9.1.3 (SAS Institute Inc., Cary, NC, USA).

\section{Results}

\section{Patient characteristics}

Of the 1,489,484 patients with an initial amlodipine/ atorvastatin or statin claim, 13,343 met all criteria for inclusion. Among these, 1139 patients from the amlodipine/ atorvastatin switch cohort were matched in a 1:3 ratio with statin add-on patients (1139 amlodipine/atorvastatin switch and 3417 statin add-on) using the propensity score matching method, to yield a final sample of 4,556 patients. Baseline characteristics for the pre-match and post-match cohorts are shown in Table 1. After matching, patient characteristics were similar in both groups; mean age was 53.9 years in both cohorts and approximately half were male (Table 1).

The overall severity of illness (measured using the Charlson Comorbidity Index) was similar between groups, although a slightly higher proportion of patients in the amlodipine/atorvastatin switch cohort was classified as having primary CVD prevention status (ie, no history of CV events) than in the statin add-on cohort $(87.4 \%$ vs $82.1 \% ; P<0.001$ ) (Table 1). Significantly fewer patients in the amlodipine/atorvastatin switch cohort than in the statin add-on cohort had a history of angina (4.7\% vs $8.0 \%$, respectively; $P<0.001)$ and a history of revascularization procedures $(1.4 \%$ vs $4.5 \% ; P<0.001)$ at index. In addition, the differences in the incidence of comorbid cancer and prior MI between groups approached significance ( $p=0.062$ and 0.073 , respectively). The proportion of patients with pre-index amlodipine adherence (PDC $\geq 0.80)$ was significantly lower in the amlodipine/atorvastatin switch cohort than in the statin add-on cohort $(52.4 \%$ vs $71.4 \% ; P<0.001)$. The mean number of pre-index 
Table I Characteristics for pre- and post-match patient cohorts

\begin{tabular}{|c|c|c|c|c|c|}
\hline \multirow[t]{2}{*}{ Characteristics } & \multicolumn{2}{|l|}{ Pre-match } & \multicolumn{3}{|l|}{ Post-match } \\
\hline & $\begin{array}{l}\text { Amlodipine/ } \\
\text { atorvastatin } \\
\text { switch } \\
(n=|| 77)\end{array}$ & $\begin{array}{l}\text { Statin add-on } \\
(n=12,166)\end{array}$ & $\begin{array}{l}\text { Amlodipine/ } \\
\text { atorvastatin } \\
\text { switch } \\
(n=1 / 39)\end{array}$ & $\begin{array}{l}\text { Statin add-on } \\
(n=34 I 7)\end{array}$ & $\begin{array}{l}\text { P-value } \\
\text { between } \\
\text { matched } \\
\text { cohorts }\end{array}$ \\
\hline Age $^{a}$, years & $53.5 \pm 8.9$ & $56.1 \pm 10.2$ & $53.9 \pm 8.7$ & $53.9 \pm 8.1$ & 0.498 \\
\hline Gender ${ }^{\mathrm{a}}$, male & $631(53.6)$ & $6257(51.4)$ & $614(53.9)$ & $1760(5 \mid .5)$ & 0.160 \\
\hline Geographic region ${ }^{a}$ & & & & & 0.509 \\
\hline Northeast & $407(34.6)$ & $3968(32.6)$ & $40 \mathrm{I}(35.2)$ & $1282(37.5)$ & \\
\hline Midwest & $281(23.9)$ & 459। (37.7) & $28 I(24.7)$ & $823(24.1)$ & \\
\hline South & $465(39.5)$ & $3264(26.8)$ & $433(38.0)$ & $1234(36.1)$ & \\
\hline West & $24(2.0)$ & $343(2.8)$ & $24(2.1)$ & $78(2.3)$ & \\
\hline \multicolumn{6}{|l|}{ CVD status } \\
\hline Primary prevention ${ }^{\mathrm{b}}$ & $1032(87.7)$ & $9445(77.6)$ & $995(87.4)$ & $2804(82.1)$ & $<0.001$ \\
\hline Plan type ${ }^{a}$ & & & & & 0.439 \\
\hline Health maintenance organization & $264(22.4)$ & $394 I(32.4)$ & $264(23.2)$ & $802(23.5)$ & \\
\hline Preferred provider organization & $635(54.0)$ & $5168(42.5)$ & $598(52.5)$ & $1730(50.6)$ & \\
\hline Point of service & $180(15.3)$ & $2054(16.9)$ & $179(15.7)$ & $527(15.4)$ & \\
\hline Indemnity plan & $79(6.7)$ & $77 \mid(6.3)$ & $79(6.9)$ & $294(8.6)$ & \\
\hline Unknown & $19(1.6)$ & $232(1.9)$ & $19(1.7)$ & $64(1.9)$ & \\
\hline Payer type ${ }^{a}$ & & & & & 0.290 \\
\hline Commercial & $1074(9 \mid .2)$ & 10,076 (82.8) & $1036(91.0)$ & $3104(90.8)$ & \\
\hline Medicaid & $\mathrm{I}(0.1)$ & $119(1.0)$ & $\mathrm{I}(0.1)$ & $3(0.1)$ & \\
\hline Medicare risk & $47(4.0)$ & $1258(10.3)$ & $47(4.1)$ & $108(3.2)$ & \\
\hline Self-insured & $49(4.2)$ & $662(5.4)$ & $49(4.3)$ & $188(5.5)$ & \\
\hline Unknown & $6(0.5)$ & $5 \mathrm{I}(0.4)$ & $6(0.5)$ & $14(0.4)$ & \\
\hline Charlson comorbidity index ${ }^{a}$ & $0.9 \pm 1.4$ & $1.2 \pm 1.6$ & $0.9 \pm 1.4$ & $0.9 \pm 1.3$ & 0.867 \\
\hline $\begin{array}{l}\text { Number of pre-index } \mathrm{AH} \text { drug } \\
\text { classes }^{\mathrm{a}}\end{array}$ & $0.7 \pm 0.8$ & $0.8 \pm 0.8$ & $0.7 \pm 0.8$ & $0.7 \pm 0.7$ & 0.777 \\
\hline \multicolumn{6}{|l|}{ Co-morbidities of interest } \\
\hline Cancer & $70(5.9)$ & $874(7.2)$ & $70(6.1)$ & $162(4.7)$ & 0.062 \\
\hline Diabetes mellitus & $311(26.4)$ & $3854(31.7)$ & $310(27.2)$ & $892(26.1)$ & 0.461 \\
\hline Dyslipidemia & $879(74.7)$ & $866 \mid(7 \mid .2)$ & 851 (74.7) & $2459(72.0)$ & 0.071 \\
\hline Obesity & $94(8.0)$ & $1083(8.9)$ & $92(8.1)$ & $262(7.7)$ & 0.655 \\
\hline Chronic renal failure & $47(4.0)$ & $772(6.3)$ & $46(4.0)$ & $125(3.7)$ & 0.559 \\
\hline Heart failure ${ }^{c}$ & $36(3.1)$ & $783(6.4)$ & $36(3.2)$ & $142(4.2)$ & 0.133 \\
\hline Myocardial infarction & $24(2.0)$ & $548(4.5)$ & $24(2.1)$ & $107(3.1)$ & 0.073 \\
\hline Angina (unstable and pectoris) & $55(4.7)$ & $1105(9.1)$ & $54(4.7)$ & $272(8.0)$ & $<0.001$ \\
\hline Other ischemic heart disease & $8(0.7)$ & II $14(0.9)$ & $8(0.7)$ & $23(0.7)$ & 0.917 \\
\hline $\begin{array}{l}\text { Ischemic stroke/transient } \\
\text { ischemic attack }\end{array}$ & $65(5.5)$ & $1094(9.0)$ & $65(5.7)$ & $232(6.8)$ & 0.200 \\
\hline Peripheral vascular disease & $57(4.8)$ & $760(6.2)$ & $57(5.0)$ & $153(4.5)$ & 0.463 \\
\hline COPD & $55(4.7)$ & $800(6.6)$ & $54(4.7)$ & $168(4.9)$ & 0.812 \\
\hline \multicolumn{6}{|l|}{ Procedures of interest } \\
\hline Revascularization & $16(1.4)$ & $588(4.8)$ & $16(1.4)$ & $153(4.5)$ & $<0.001$ \\
\hline Endarterectomy & $2(0.2)$ & $24(0.2)$ & $2(0.2)$ & $6(0.2)$ & 1.000 \\
\hline $\begin{array}{l}\text { Pre-index amlodipine } \\
\text { prescriptions }\end{array}$ & - & - & $5.2 \pm 3.6$ & $5.5 \pm 3.8$ & 0.059 \\
\hline
\end{tabular}


Table I (Continued)

\begin{tabular}{|c|c|c|c|c|c|}
\hline \multirow[t]{2}{*}{ Characteristics } & \multicolumn{2}{|l|}{ Pre-match } & \multicolumn{3}{|l|}{ Post-match } \\
\hline & $\begin{array}{l}\text { Amlodipine/ } \\
\text { atorvastatin } \\
\text { switch } \\
(\mathrm{n}=\mid \text { I } 77)\end{array}$ & $\begin{array}{l}\text { Statin add-on } \\
(n=12,166)\end{array}$ & $\begin{array}{l}\text { Amlodipine/ } \\
\text { atorvastatin } \\
\text { switch } \\
(\mathrm{n}=\text { I I39) }\end{array}$ & $\begin{array}{l}\text { Statin add-on } \\
(n=3417)\end{array}$ & $\begin{array}{l}P \text {-value } \\
\text { between } \\
\text { matched } \\
\text { cohorts }\end{array}$ \\
\hline $\begin{array}{l}\text { Pre-index amlodipine adherence } \\
\text { (PDC } \geq 0.80 \text { ) }\end{array}$ & - & - & $597(52.4)$ & $2439(71.4)$ & $<0.001$ \\
\hline Pre-index amlodipine PDC & - & - & $0.73 \pm 0.3$ & $0.83 \pm 0.21$ & $<0.001$ \\
\hline $\begin{array}{l}\text { Days between first pre-index } \\
\text { amlodipine script and index date }\end{array}$ & - & - & $258.5 \pm 110.0$ & $236.7 \pm 124.7$ & $<0.001$ \\
\hline
\end{tabular}

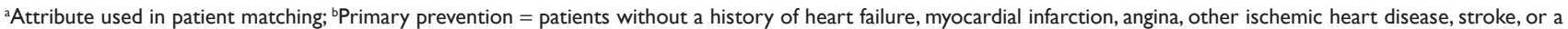
revascularization or endarterectomy procedure; ${ }^{\mathrm{C} W}$ ith or without chronic kidney disease.

Notes: Data are mean \pm standard deviation or $\mathrm{n}(\%)$, unless otherwise indicated.

Abbreviations: $\mathrm{AH}$, antihypertensive; COPD, chronic obstructive pulmonary disease; CVD, cardiovascular disease; PDC, proportion of days covered.

antihypertensive classes was similar between the two matched patient cohorts.

\section{Proportion of patients achieving adherence}

At 180 days post-index follow-up, the proportion of patients achieving adherence ( $\mathrm{PDC} \geq 0.80$ ) with statin therapy was significantly higher for the amlodipine/atorvastatin switch cohort compared with the statin add-on cohort $(50.8 \%$ vs $44.3 \% P<0.001$; Table 2).

In multivariable logistic regression modeling, patients who switched to amlodipine/atorvastatin had 1.64-times greater odds of achieving adherence with their statin therapy than those receiving a statin as add-on therapy $(P<0.001$; Figure 1$)$, after adjusting for pre-index adherence ( $\mathrm{PDC} \geq 0.80$ ) with amlodipine and CVD prevention status (primary vs secondary). As expected, patients with pre-index amlodipine adherence were significantly more likely to achieve post-index adherence with statin therapy than those defined as non-adherent (odds ratio $[\mathrm{OR}]=2.95,95 \%$ confidence interval $[\mathrm{CI}]=2.57,3.37 ; P<0.001$; Figure 1 ). Among all patients, $50.8 \%$ of the switch cohort and $44.3 \%$ of the statin add-on cohort were adherent $(P D C \geq 0.80)$ at 180-day follow-up (Table 2).

\section{Persistence with therapy}

Persistence with statin therapy in the 180-day post-index period was superior in the amlodipine/atorvastatin switch cohort vs the statin add-on cohort (Figure 2). The mean number of days patients were persistent with therapy in the amlodipine/atorvastatin switch cohort was 127.6 days compared with 116.9 days in the statin add-on cohort $(P<0.001)$ (Table 2). Similarly, when restricted to those patients with $\geq 2$ prescriptions, the mean persistence was significantly better among patients in the amlodipine/ atorvastatin switch cohort compared with the statin add-on cohort (143.0 vs 135.0 days; $P<0.001$ ).

\section{Overall statin and amlodipine exposure}

When a sensitivity analysis was conducted to assess any amlodipine use (including amlodipine received as part of the single-pill combination or as amlodipine alone) in each cohort during the study period, more patients in the amlodipine/atorvastatin switch cohort achieved post-index adherence ( $\mathrm{PDC} \geq 0.80$ ) for any amlodipine use compared with the statin add-on cohort $(59.5 \%$ vs $42.5 \%$; $P<0.001)$ (Table 3). Among amlodipine users filling $\geq 2$ prescriptions, mean PDC for amlodipine use in the amlodipine/atorvastatin switch cohort was higher vs the statin add-on cohort ( $0.80 \mathrm{vs}$ $0.75 ; P<0.001)$.

Similarly, when any statin use was assessed (including statin therapy received as part of the single-pill combination or as any statin alone) during the study period, more patients in the switch cohort achieved post-index adherence ( $\mathrm{PDC} \geq 0.80$ ) for any statin compared with the statin add-on cohort (53.8\% vs $45.0 \%$; $P<0.001$ ) (Table 3). Mean PDC for any statin was also higher for the switch cohort compared with the add-on cohort among patients filling two or more prescriptions $(0.79$ vs $0.75 ; P<0.003)$.

\section{Discussion}

This study demonstrates that for patients prescribed amlodipine, switching to single-pill amlodipine/atorvastatin resulted in higher adherence with statin therapy when compared to adding a separate statin to their current antihypertensive regimen. Furthermore, the adherence benefit in the amlodipine/atorvastatin switch cohort remained even 
Table 2 Adherence patterns by index regimen at 180-days follow-up

\begin{tabular}{|c|c|c|c|}
\hline Characteristic & $\begin{array}{l}\text { Amlodipine/ } \\
\text { atorvastatin switch } \\
(\mathrm{n}=\text { II39) }\end{array}$ & $\begin{array}{l}\text { Statin add-on } \\
(n=34 \mid 7)\end{array}$ & $P$-value ${ }^{a}$ \\
\hline Number of post-index medication prescriptions & $3.76 \pm 1.99$ & $3.44 \pm 1.99$ & $<0.001$ \\
\hline \multicolumn{4}{|l|}{ Among all patients } \\
\hline Post-index adherence (PDC $\geq 0.80)$ & $579(50.8)$ & $1514(44.3)$ & $<0.001$ \\
\hline Post-index adherence, PDC & $0.70 \pm 0.28$ & $0.65 \pm 0.29$ & $<0.001$ \\
\hline Days supply post-index & $125.6 \pm 50.1$ & $117.2 \pm 52.8$ & $<0.001$ \\
\hline Persistence, days & $127.6 \pm 61.7$ & $116.9 \pm 63.4$ & $<0.001$ \\
\hline \multicolumn{4}{|l|}{ Among patients with $2+$ prescriptions } \\
\hline Number of patients & $958(84.1)$ & $2715(79.5)$ & \\
\hline Post-index adherence, PDC & $0.78 \pm 0.21$ & $0.75 \pm 0.23$ & 0.010 \\
\hline Days supply post-index & $140.7 \pm 37.7$ & $135.3 \pm 41.4$ & 0.010 \\
\hline Persistence, days & $143.0 \pm 53.8$ & $135.0 \pm 57.4$ & $<0.001$ \\
\hline
\end{tabular}

Notes: Data are mean \pm standard deviation or $\mathrm{n}(\%)$. ${ }^{\mathrm{C} C o m p a r i s o n}$ of amlodipine/atorvastatin vs statin add-on.

Abbreviation: PDC, proportion of days covered.

after adjusting for pre-index amlodipine adherence and for any amlodipine or statin use during the study. Persistence with statin therapy was also significantly longer for patients who switched to amlodipine/atorvastatin compared with those in the statin add-on cohort.

These observations are in agreement with an earlier study demonstrating that patients who were previously naïve to both antihypertensive and statin therapy were more likely to be adherent and persistent with single-pill amlodipine/atorvastatin than with a calcium channel blocker and statin prescribed as two separate pills (including coadministered amlodipine and atorvastatin).${ }^{29}$ Furthermore, our data are in line with studies demonstrating that an increase in the number of medications or dosing frequency is inversely related to adherence, ${ }^{21,37-40}$ and with previous analyses suggesting that the use of single-pill combination agents helps improve medication adherence in patients with chronic conditions such as tuberculosis, HIV, and diabetes, as well as hypertension. ${ }^{17,22,41}$ However, it should be noted that the relationship between adherence and number of pills is not necessarily linear, and some studies have conversely shown that being prescribed a higher number of pills is associated with greater adherence. ${ }^{42,43}$ A potential explanation for this is that patients on the highest numbers of medications are often those with more serious or treatmentresistant conditions, and a greater overall severity of illness may be associated with better adherence. ${ }^{44}$

Other potential reasons for the adherence benefits of single-pill amlodipine/atorvastatin, observed in both the current analysis and our previous study, ${ }^{29}$ include the synchronization of antihypertensive and statin therapy initiation, ${ }^{25}$ and the lower number of copayments associated with the single-pill vs two pills, both of which have been shown to influence adherence in previous analyses. ${ }^{45-48}$ Interestingly, the proportion of patients adherent with pre-index amlodipine was significantly lower in the amlodipine/atorvastatin switch cohort than in the statin add-on cohort, which raises the possibility that physicians already recognize some of these potential adherence benefits with single-pill amlodipine/atorvastatin and preferentially select patients with poor adherence to start on the single-pill formulation.

Some of the improvement in statin adherence conferred by switching from amlodipine to single-pill amlodipine/ atorvastatin vs adding a separate statin in this study may result from altering patients' perception of their statin therapy. Previous investigations have demonstrated that adherence with statin therapy is generally poor, ${ }^{16,34,36,49}$ and that statin adherence is lower than adherence with antihypertensives. ${ }^{21}$ Several possible factors may be responsible for patients' apparent reluctance to take statin therapy as prescribed; most likely this is due to a combination of concerns over potential adverse events and a perceived lack of therapeutic benefit. ${ }^{50,51}$ Additionally, the BP-lowering benefits of antihypertensive drugs can be more immediately monitored, which may help reinforce patients' awareness of the therapeutic benefits of their antihypertensive medications. In particular, self-monitoring of BP using home-monitoring has been associated with improved adherence with therapy. ${ }^{52,53}$ In contrast, such immediate feedback cannot be provided for lipid-lowering therapy, which may limit the perceived benefit for the patient. 


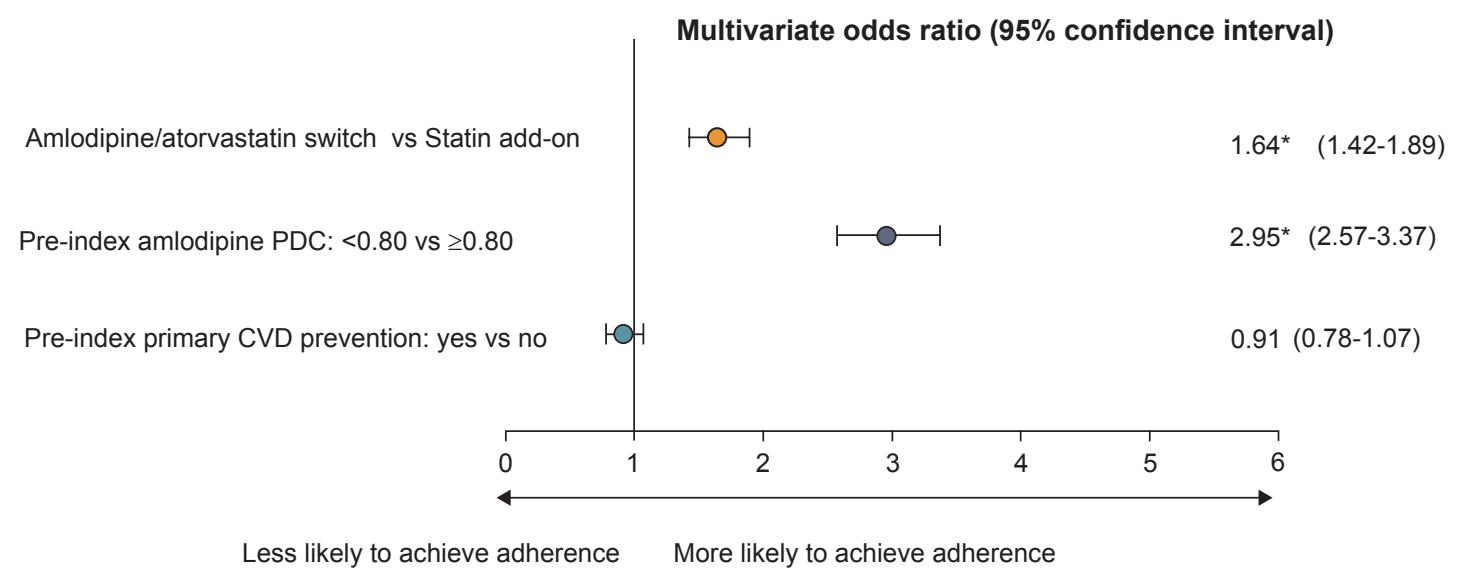

Figure I Adjusted odds ratio ( $95 \%$ confidence interval) of achieving adherence (proportion of days covered [PDC] $\geq 0.80$ ) with statin therapy at I80-day follow-up. Note: $* P<0.001$ for group comparison parameter estimate in the regression.

Abbreviation: CVD, cardiovascular disease.

Our data support the hypothesis that the use of single-pill amlodipine/atorvastatin could help to improve adherence with statin therapy by promoting adherence to the levels achieved with antihypertensive therapy. For example, the proportion of patients adherent with statin therapy at 6 months after initiating therapy in this study was $44 \%$ in the statin add-on cohort, comparable with the proportion of patients adherent with statin therapy in our previous analysis $(43 \%) ;{ }^{21}$ in contrast, the proportion adherent with statin therapy in the single-pill cohort was 51\%, which approaches the proportion adherent with antihypertensives in our earlier investigation (58\%). ${ }^{21}$

This study should be interpreted in light of some limitations. As with any retrospective, non-randomized comparison between groups, selection bias may have resulted in more adherent patients receiving amlodipine/atorvastatin than statin add-on therapy. However, the propensity score matching

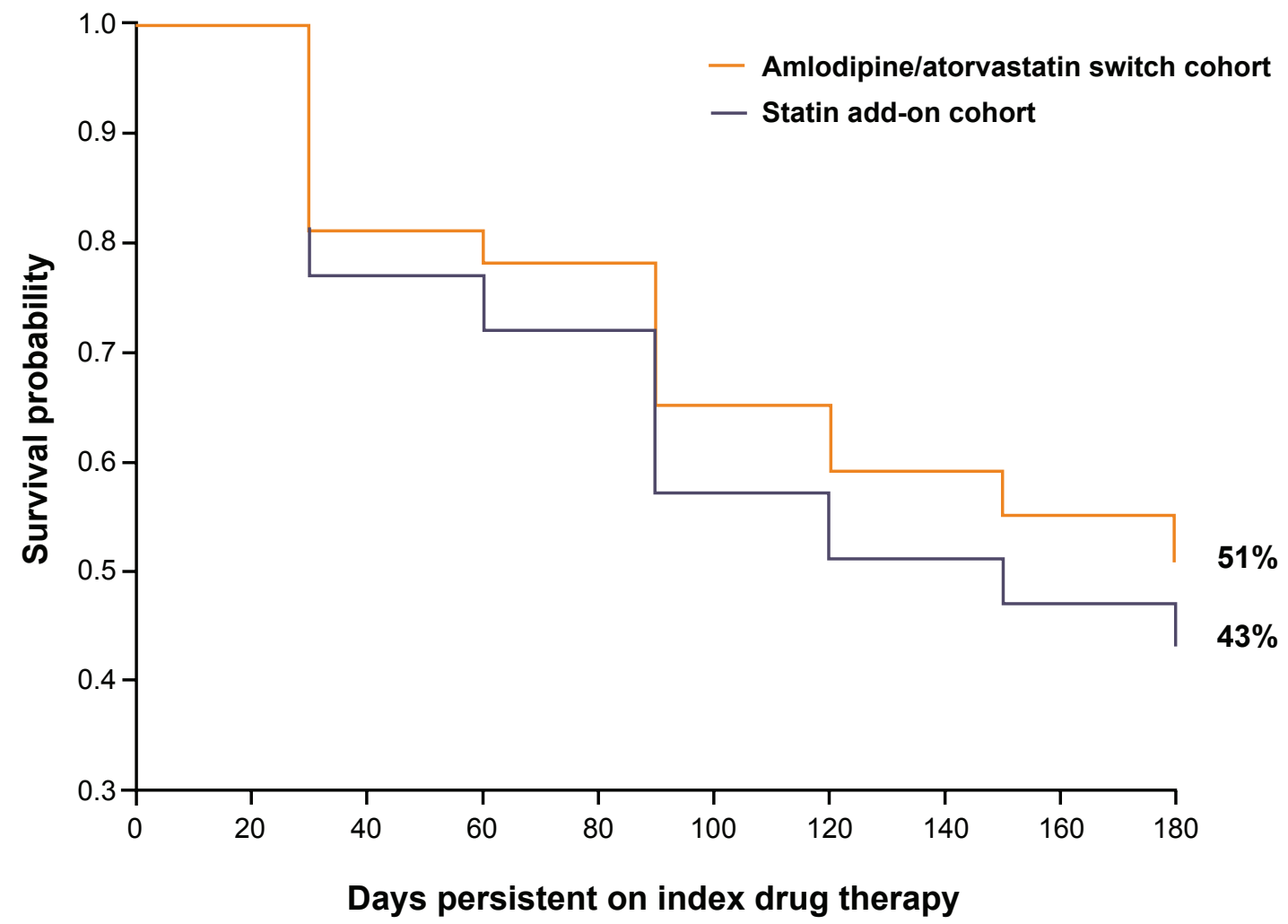

Figure 2 Kaplan-Meier graph showing persistence with therapy for patients in amlodipine/atorvastatin switch and statin add-on cohorts, during 180 -day follow-up. 
Table 3 Adherence by class-level exposure: sensitivity analysis

\begin{tabular}{|c|c|c|c|c|c|c|}
\hline \multirow[t]{2}{*}{ Characteristic } & \multicolumn{3}{|c|}{ Any amlodipine use ${ }^{a}$} & \multicolumn{3}{|c|}{ Any statin use ${ }^{b}$} \\
\hline & $\begin{array}{l}\text { Amlodipine/ } \\
\text { atorvastatin } \\
\text { switch } \\
(n=\text { I I39) }\end{array}$ & $\begin{array}{l}\text { Statin add-on } \\
(\mathrm{n}=3417)\end{array}$ & $P$-value & $\begin{array}{l}\text { Amlodipine/ } \\
\text { atorvastatin } \\
\text { switch } \\
(\mathrm{n}=\text { I I39) }\end{array}$ & $\begin{array}{l}\text { Statin add-on } \\
(n=34 \mid 7)\end{array}$ & $P$-value \\
\hline \multicolumn{7}{|l|}{ Among all patients } \\
\hline Post-index adherence (PDC $\geq 0.80$ ) & $678(59.5)$ & $1453(42.5)$ & $<0.001$ & $613(53.8)$ & $1536(45.0)$ & $<0.001$ \\
\hline Post-index adherence, PDC & $0.76 \pm 0.24$ & $0.64 \pm 0.29$ & $<0.001$ & $0.72 \pm 0.27$ & $0.66 \pm 0.29$ & $<0.001$ \\
\hline Days supply post-index & $137.0 \pm 43.7$ & $116.0 \pm 51.8$ & $<0.001$ & $129.5 \pm 48.2$ & $118.1 \pm 52.6$ & $<0.001$ \\
\hline \multicolumn{7}{|l|}{ Among patients with } \\
\hline \multicolumn{7}{|l|}{$2+$ prescriptions } \\
\hline Number of patients & $1053(92.4)$ & $2770(81.1)$ & & $994(87.3)$ & $2739(80.2)$ & \\
\hline Post-index adherence, PDC & $0.80 \pm 0.20$ & $0.75 \pm 0.18$ & $<0.001$ & $0.79 \pm 0.21$ & $0.75 \pm 0.23$ & 0.003 \\
\hline Days supply post-index & $144.5 \pm 35.4$ & $135.2 \pm 32.3$ & $<0.001$ & $|4| .8 \pm 37.1$ & $135.7 \pm 41.3$ & 0.003 \\
\hline
\end{tabular}

Notes: Data are mean \pm standard deviation or $\mathrm{n}(\%)$. ${ }^{a}$ Includes prescriptions for amlodipine (generic or Norvasc ${ }^{\circledR}$ [Pfizer Inc, New York, NY]), or single-pill amlodipine/atorvastatin in either cohort; ' 'ncludes prescriptions for any statin or single-pill amlodipine/atorvastatin in either cohort. Abbreviation: PDC, proportion of days covered.

process enabled adjustment for observable predictors of treatment assignment, with the exclusion of patients who could not be well matched. In addition, as mentioned above, a higher proportion of patients in the statin add-on cohort were adherent with amlodipine in the pre-index period, suggesting that in fact this cohort might have been expected to be more adherent with treatment than the amlodipine/atorvastatin switch cohort.

Prior to propensity score matching, patients in the statin add-on group had a higher incidence of comorbidities than in the amlodipine/atorvastatin switch group, and some differences remained post-matching. For example, a slightly higher proportion of patients in the statin add-on group had a history of CVD than in the amlodipine/atorvastatin switch group, and there were significantly more patients with angina and revascularization procedures in the add-on vs the switch group. The between-group differences in the proportion of patients with cancer or prior MI also approached significance. However, the overall severity of illness was similar between the matched cohorts. Furthermore, we demonstrated that primary CVD prevention status was not a predictor of adherence in this study, and is therefore unlikely to have had a substantial impact on the results observed.

An inherent limitation of all claims data analyses is reliance on accurate $I C D-9-C M$ coding, leading to the potential for under- or over-reporting of certain conditions. For example, obesity is often under-coded, and thus accurate adjustments for the incidence of obesity or the metabolic syndrome between groups were not possible. However, other cardiovascular comorbidities and overall severity of illness were included as variables in the propensity score matching and thus the proportion of patients with such cardiovascular risk factors was likely to have been similar between groups. In addition, under-coding of hypertension may have led to the exclusion of some otherwise eligible patients, but this exclusion criterion avoided the inclusion of patients who were prescribed amlodipine for the treatment of angina. Other limitations include the fact that patients aged $\geq 65$ years who were not enrolled in a Medicare Risk plan were excluded; thus the proportion of elderly patients, who are likely to be in poorer overall health and taking more concomitant medications, is likely to be lower in this analysis than in clinical practice. Data for the uninsured or patients in long-term care settings, such as nursing homes and hospices, were also not available in the database, which may limit the generalizability of these data to these potentially higher risk populations.

Assessing adherence based on prescription refill rates is a proxy measure only, and a patient's true pattern of medication-taking may still be unknown. However, studies of the validity of refill rates as an adherence measure have shown that refill rates are significantly associated with clinical measures of adherence such as serum drug levels. ${ }^{54}$ Furthermore, although the primary categorization of adherence based on a PDC $\geq 0.80$ was arbitrary, this cut point is a commonly accepted definition of medication adherence in studies using pharmacy refill records. ${ }^{16,19,21,29,34-36}$ It was not possible to assess therapeutic outcomes or adverse events 
in this study due to an inability to cross-reference lab test data with prescription claims in this database. Previous research has provided evidence that higher adherence with antihypertensive and lipid-lowering medications is associated with better clinical efficacy and outcomes in the long-term; ${ }^{17-20}$ however, further investigations should aim to confirm that the specific adherence benefits of amlodipine/atorvastatin translate to improved therapeutic efficacy.

As only pre-index variables were included in the propensity score matching model, it was not possible to adjust for post-index variables such as the use of generic vs branded products or copayment costs, both of which have previously been suggested to impact on medication adherence ${ }^{55,56}$ However, as payer and plan type were included in the propensity score matching, differences in the use of generic products and drug-specific copayment costs would be accounted for at the insurance plan level. Moreover, as discussed above, the reduced number of copayments with single-pill therapy was considered part of the therapeutic package affecting adherence in the two study groups, and was therefore not adjusted for in these analyses.

Given the potential influence on adherence of using generic vs branded products, ${ }^{55,56}$ it should also be noted that patent protection on amlodipine ended in September 2007 and that subsequently generic amlodipine has been widely available. As this fell outside of the study period for this analysis (July 1, 2004 to June 30, 2007), this would not have influenced the results of our study. However, the availability of generic amlodipine in current clinical practice should be considered in future analyses and when interpreting these results.

Despite the limitations of this study, the data presented provide evidence that the use of single-pill amlodipine/ atorvastatin combination therapy to integrate statin therapy with ongoing antihypertensive treatment helps to improve adherence with lipid-lowering therapy to the levels of adherence observed with antihypertensives. By switching new statin user from their existing amlodipine therapy to singlepill amlodipine/atorvastatin, it is possible that patients maintain positive perceptions of their antihypertensive therapy, and that this, in combination with reduced pill burden and the synchronization of therapy, contributes to greater adherence compared with adding a separate statin.

\section{Conclusion}

Single-pill amlodipine/atorvastatin combination therapy has the potential to improve adherence with statin therapy, perhaps by conferring the greater level of adherence observed with antihypertensives such as amlodipine. When adding statin therapy in patients with hypertension who are already receiving amlodipine, clinicians should consider the potential benefits to therapy adherence afforded by single-pill amlodipine/atorvastatin.

\section{Acknowledgments and disclosures}

This study was sponsored by Pfizer Inc. Editorial support was provided by Karen Burrows and Elizabeth Harvey of UBC Scientific Solutions, and funded by Pfizer Inc. Dr RH Chapman, Ms EM Pelletier, and Ms PJ Smith of IMS Health were paid consultants to Pfizer Inc in connection with the development of the manuscript. Dr. CS Roberts is an employee of Pfizer Inc.

\section{References}

1. Rosamond W, Flegal K, Furie K, et al. Heart disease and stroke statistics-2008 update: a report from the American Heart Association Statistics Committee and Stroke Statistics Subcommittee. Circulation. 2008;117(4):e25-e146.

2. Neaton JD, Wentworth D. Serum cholesterol, blood pressure, cigarette smoking, and death from coronary heart disease. Overall findings and differences by age for 316,099 white men. Multiple Risk Factor Intervention Trial Research Group. Arch Intern Med. 1992;152(1): 56-64.

3. Thomas F, Bean K, Guize L, Quentzel S, Argyriadis P, Benetos A. Combined effects of systolic blood pressure and serum cholesterol on cardiovascular mortality in young $(<55$ years $)$ men and women. Eur Heart J. 2002;23(7):528-535.

4. Neaton JD, Blackburn H, Jacobs D, et al. Serum cholesterol level and mortality findings for men screened in the Multiple Risk Factor Intervention Trial. Multiple Risk Factor Intervention Trial Research Group. Arch Intern Med. 1992;152(7):1490-1500.

5. Eaton CB, Feldman HA, Assaf AR, et al. Prevalence of hypertension, dyslipidemia, and dyslipidemic hypertension. J Fam Pract. 1994;38(1):17-23.

6. Wong ND, Lopez V, Tang S, Williams GR. Prevalence, treatment, and control of combined hypertension and hypercholesterolemia in the United States. Am J Cardiol. 2006;98(2):204-208.

7. O’Meara JG, Kardia SL, Armon JJ, Brown CA, Boerwinkle E, Turner ST. Ethnic and sex differences in the prevalence, treatment, and control of dyslipidemia among hypertensive adults in the GENOA study. Arch Intern Med. 2004;164(12):1313-1318.

8. Turnbull F. Effects of different blood-pressure-lowering regimens on major cardiovascular events: results of prospectively-designed overviews of randomised trials. Lancet. 2003;362(9395):1527-1535.

9. Staessen JA, Wang JG, Thijs L. Cardiovascular prevention and blood pressure reduction: a quantitative overview updated until 1 March 2003. J Hypertens. 2003;21(6):1055-1076.

10. Sever PS, Dahlöf B, Poulter NR, et al. Prevention of coronary and stroke events with atorvastatin in hypertensive patients who have average or lower-than-average cholesterol concentrations, in the Anglo-Scandinavian Cardiac Outcomes Trial-Lipid Lowering Arm (ASCOT-LLA): a multicentre randomised controlled trial. Lancet. 2003;361(9364):1149-1158.

11. Baigent C, Keech A, Kearney PM, et al. Efficacy and safety of cholesterol-lowering treatment: prospective meta-analysis of data from 90,056 participants in 14 randomised trials of statins. Lancet. 2005;366(9493):1267-1278. 
12. ALLHAT Officers and Coordinators for the ALLHAT Collaborative Research Group. Major outcomes in high-risk hypertensive patients randomized to angiotensin-converting enzyme inhibitor or calcium channel blocker vs diuretic: The Antihypertensive and LipidLowering Treatment to Prevent Heart Attack Trial (ALLHAT). JAMA. 2002;288(23):2981-2997.

13. Johnson ML, Pietz K, Battleman DS, Beyth RJ. Therapeutic goal attainment in patients with hypertension and dyslipidemia. Med Care. 2006;44(1):39-46.

14. European Society of Hypertension-European Society of Cardiology Guidelines Committee. 2003 European Society of HypertensionEuropean Society of Cardiology guidelines for the management of arterial hypertension. J Hypertens. 2003;21(6):1011-1053.

15. Kotseva K, Wood D, De Backer G, De Bacquer D, Pyorala K, Keil U. EUROASPIRE III: a survey on the lifestyle, risk factors and use of cardioprotective drug therapies in coronary patients from 22 European countries. Eur J Cardiovasc Prev Rehabil. 2009;16(2):121-137.

16. Benner JS, Pollack MF, Smith TW, Bullano MF, Willey VJ, Williams SA. Association between short-term effectiveness of statins and long-term adherence to lipid-lowering therapy. Am J Health Syst Pharm. 2005;62(14):1468-1475.

17. Bramley TJ, Gerbino PP, Nightengale BS, Frech-Tamas F. Relationship of blood pressure control to adherence with antihypertensive monotherapy in 13 managed care organizations. J Manag Care Pharm. 2006;12(3): 239-245.

18. Ho PM, Magid DJ, Shetterly SM, et al. Importance of therapy intensification and medication nonadherence for blood pressure control in patients with coronary disease. Arch Intern Med. 2008;168(3):271-276.

19. Ho PM, Rumsfeld JS, Masoudi FA, et al. Effect of medication nonadherence on hospitalization and mortality among patients with diabetes mellitus. Arch Intern Med. 2006;166(17):1836-1841.

20. Ho PM, Spertus JA, Masoudi FA, et al. Impact of medication therapy discontinuation on mortality after myocardial infarction. Arch Intern Med. 2006;166(17):1842-1847.

21. Chapman RH, Benner JS, Petrilla AA, et al. Predictors of adherence with antihypertensive and lipid-lowering therapy. Arch Intern Med. 2005;165(10):1147-1152.

22. Dezii CM. A retrospective study of persistence with single-pill combination therapy vs concurrent two-pill therapy in patients with hypertension. Manag Care. 2000;9(9 Suppl):2-6.

23. Perreault S, Lamarre D, Blais L, et al. Persistence with treatment in newly treated middle-aged patients with essential hypertension. Ann Pharmacother. 2005;39(9):1401-1408.

24. Taylor AA, Shoheiber O. Adherence to antihypertensive therapy with fixed-dose amlodipine besylate/benazepril $\mathrm{HCl}$ versus comparable component-based therapy. Congest Heart Fail. 2003;9(6):324-332.

25. Agarwal S, Tang SSK, Rosenberg N, et al. Does synchronizing initiation of therapy affect adherence to concomitant use of antihypertensive and lipid-lowering therapy? Am J Ther. 2009;16(2):119-126.

26. Neutel JM, Bestermann WH, Dyess EM, et al. The use of a single-pill calcium channel blocker/statin combination in the management of hypertension and dyslipidemia: a randomized, placebo-controlled, multicenter study. J Clin Hypertens (Greenwich). 2009;11(1):22-30.

27. Flack JM, Victor R, Watson K, et al. Improved attainment of blood pressure and cholesterol goals using single-pill amlodipine/atorvastatin in African Americans: the CAPABLE trial. Mayo Clin Proc. 2008;83(1):35-45.

28. Erdine S, Ro YM, Tse HF, et al. Single-pill amlodipine/atorvastatin helps patients of diverse ethnicity attain recommended goals for blood pressure and lipids (the Gemini-AALA study). J Hum Hypertens. 2008;23(3):196-210.

29. Patel BV, Leslie RS, Thiebaud P, et al. Adherence with single-pill amlodipine/atorvastatin vs a two-pill regimen. Vasc Health Risk Manag. 2008;4(3):673-681.

30. Joyce AT, Harrison DJ, Loebel AD, Ollendorf DA. Impact of atypical antipsychotics on outcomes of care in schizophrenia. Am J Manag Care. 2005;11(8 Suppl):S254-S261.
31. Romano PS, Roost LL, Jollis JG. Adapting a clinical comorbidity index for use with ICD-9-CM administrative data: differing perspectives. J Clin Epidemiol. 1993;46:1075-1079.

32. Weitzen S, Lapane KL, Toledano AY, Hume AL, Mor V. Principles for modeling propensity scores in medical research: a systematic literature review. Pharmacoepidemiol Drug Saf. 2004;13(12):841-853.

33. Rubin DB. Estimating causal effects from large data sets using propensity scores. Ann Intern Med. 1997;127(8 Pt 2):757-763.

34. Benner JS, Glynn RJ, Mogun H, Neumann PJ, Weinstein MC, Avorn J. Long-term persistence in use of statin therapy in elderly patients. JAMA. 2002;288(4): 455-461.

35. LaFleur J, Thompson CJ, Joish VN, Charland SL, Oderda GM, Brixner DI. Adherence and persistence with single-dosage form extended-release niacin/lovastatin compared with statins alone or in combination with extended-release niacin. Ann Pharmacother. 2006;40(7-8): 1274-1279.

36. Donnelly LA, Doney AS, Morris AD, Palmer CN, Donnan PT. Long-term adherence to statin treatment in diabetes. Diabet Med. 2008;25(7):850-855.

37. Claxton AJ, Cramer J, Pierce C. A systematic review of the associations between dose regimens and medication compliance. Clin Ther. 2001;23(8):1296-1310.

38. Benner JS, Chapman RH, Petrilla AA, Tang SSK, Rosenberg N, Schwartz S. Patients' pill burden predicts adherence to antihypertensive and lipid-lowering therapy. Am J Health Syst Pharm. 2009: in press.

39. Chapman RH, Petrilla AA, Benner JS, Schwartz JS, Tang SSK. Predictors of adherence to concomitant antihypertensive and lipid-lowering medications in older adults a retrospective, cohort study. Drugs Aging. 2008;25(10):885-892.

40. Kulkarni SP, Alexander KP, Lytle B, Heiss G, Peterson ED. Longterm adherence with cardiovascular drug regimens. Am Heart J. 2006;151(1):185-191.

41. Bangalore S, Kamalakkannan G, Parkar S, Messerli FH. Fixed-dose combinations improve medication compliance: a meta-analysis. Am J Med. 2007;120(8):713-719.

42. Grant RW, O'Leary KM, Weilburg JB, Singer DE, Meigs JB. Impact of concurrent medication use on statin adherence and refill persistence. Arch Intern Med. 2004;164(21):2343-2348.

43. Grant RW, Singer DE, Meigs JB. Medication adherence before an increase in antihypertensive therapy: a cohort study using pharmacy claims data. Clin Ther. 2005;27(6):773-781.

44. Lagi A, Rossi A, Passaleva MT, Cartei A, Cencetti S. Compliance with therapy in hypertensive patients. Intern Emerg Med. 2006;1(3):204-208.

45. Gibson TB, Mark TL, McGuigan KA, Axelsen K, Wang S. The effects of prescription drug copayments on statin adherence. Am J Manag Care. 2006;12(9):509-517.

46. Taira DA, Wong KS, Frech-Tamas F, Chung RS. Copayment level and compliance with antihypertensive medication: analysis and policy implications for managed care. Am J Manag Care. 2006;12(11): 678-683.

47. Thiebaud P, Patel BV, Nichol MB. The demand for statin: the effect of copay on utilization and compliance. Health Econ. 2008;17(1):83-97.

48. Wagner TH, Heisler M, Piette JD. Prescription drug co-payments and cost-related medication underuse. Health Econ Policy Law. 2008;3:51-67.

49. Blackburn DF, Dobson RT, Blackburn JL, Wilson TW, Stang MR, Semchuk WM. Adherence to statins, beta-blockers and angiotensinconverting enzyme inhibitors following a first cardiovascular event: a retrospective cohort study. Can J Cardiol. 2005;21(6):485-488.

50. LaRosa JH, LaRosa JC. Enhancing drug compliance in lipid-lowering treatment. Arch Fam Med. 2000;9(10):1169-1175.

51. Kiortsis DN, Giral P, Bruckert E, Turpin G. Factors associated with low compliance with lipid-lowering drugs in hyperlipidemic patients. $J$ Clin Pharm Ther. 2000;25(6):445-451.

52. Ogedegbe G, Schoenthaler A. A systematic review of the effects of home blood pressure monitoring on medication adherence. $J$ Clin Hypertens (Greenwich). 2006;8(3):174-180. 
53. Feldman R, Bacher M, Campbell N, Drover A, Chockalingam A. Adherence to pharmacologic management of hypertension. Can J Public Health. 1998;89(5):I16-I18.

54. Steiner JF, Prochazka AV. The assessment of refill compliance using pharmacy records: methods, validity, and applications. J Clin Epidemiol. 1997;50(1):105-116.
55. Harmon G, Lefante J, Krousel-Wood M. Overcoming barriers: the role of providers in improving patient adherence to antihypertensive medications. Curr Opin Cardiol. 2006;21(4):310-315.

56. Shrank WH, Hoang T, Ettner SL, et al. The implications of choice: prescribing generic or preferred pharmaceuticals improves medication adherence for chronic conditions. Arch Intern Med. 2006;166(3):332-337.

\section{Publish your work in this journal}

Patient Preference and Adherence is an international, peer-reviewed, open access journal that focusing on the growing importance of patient preference and adherence throughout the therapeutic continuum. Patient satisfaction, acceptability, quality of life, compliance, persistence and their role in developing new therapeutic modalities and compounds to optimize clinical outcomes for existing disease states are major areas of interest. This journal has been accepted for indexing on PubMed Central. The manuscript management system is completely online and includes a very quick and fair peer-review system. Visit http://www.dovepress.com/ testimonials.php to read real quotes from published authors.

\footnotetext{
Submit your manuscript here: http://www.dovepress.com/patient-preference-and-adherence-journal
} 